\title{
Business-to-Consumer Multi-Channel Distribution Policies: from Marketplace to Market-Space Management
}

\author{
Emanuela Tesser
}

\begin{abstract}
The new communication technologies, Internet in particular, allow businesses to achieve forms of virtual ubiquity, thus creating new factors in the control of market and competition spaces. These new tools generate the transition from marketplace to market-space, by eliminating physical distances and allowing access to products and services on a global scale.

The term 'click-and-mortar' denotes an integrated distribution system in which traditional distribution elements (physical stores, warehouses, stocks, information systems for distribution cycle management) are supported by tools made available by the new telecommunication technologies (online shopping, information platforms for distribution management, partnerships to run 'virtual' warehouses).

Click-and-mortar businesses are often the combination of a traditional retail business (brick-and-mortar) and an online start-up company.
\end{abstract}

Keywords: Click-and-Mortar; Brick-and-Mortar; Online Distribution; Offline Distribution; Distribution Channels; Multi-Channel Distribution; Online Prices; Market-Space Management

\section{Introduction}

The situation of structural over-supply ${ }^{1}$ characterizing many industries forces businesses to face the challenges of global competition and search for ever more sophisticated, diversified tools to reach their markets. The adoption of new digital technologies is part of this context. They allow for the reaching of markets not previously viable and add new communications and distribution channels to markets already served.

The new communication technologies, Internet in particular, allow businesses to achieve forms of virtual ubiquity ${ }^{2}$, thus creating new factors in the control of market and competition spaces. These new tools generate the transition from marketplace to market-space, by eliminating physical distances ${ }^{3}$ and allowing access to products and services on a global scale. This leads to new forms of

${ }^{*}$ Lecturer in Management, University of Milan-Bicocca (emanuela.tesser@unimib.it)

Edited by: ISTEI - University of Milan-Bicocca

ISSN: $1593-0319$

Tesser Emanuela, Business-to-Consumer Multi-Channel Distribution Policies: from Marketplace to Market-Space Management, Symphonya. Emerging Issues in Management (symphonya.unimib.it), n. 1, 2002, pp. 99-111 
competition which affect marketing operational tools by establishing virtual distribution networks alongside physical networks (click-and-mortar distribution), for companies already present in the market with physical stores (onland distribution), and for pioneers of e-commerce (online distribution).

The most recent trend is multi-channel management, in which several distribution channels are used to access the same markets, through various forms of integration (at the level of communication, promotion and distribution) or by resorting to electronic channels to access markets that are far away or not yet sufficiently profitable.

\section{Click-and-Mortar Businesses}

The term 'click-and-mortar' denotes an integrated distribution system in which traditional distribution elements (physical stores, warehouses, stocks, information systems for distribution cycle management) are supported by tools made available by the new telecommunication technologies (online shopping, information platforms for distribution management, partnerships to run 'virtual' warehouses). The expression combines the words click (highlighting the virtual aspect) and mortar (highlighting the physical aspect), thus highlighting the integration of Internet-based (online) business and traditional (onland) elements ${ }^{4}$.

Click-and-mortar businesses are often the combination of a traditional retail business (brick-and-mortar) and an online start-up business. The former can count on market experience, awareness-related assets and brand equity, while the latter contributes knowledge and investments in innovative technology. 'Click' represents the online world: 'dot.com' and 'e-tailer' businesses characterized by innovation, high turnover, potential for development of one-to-one marketing, and ability to reduce the structural and workforce costs that characterize brick-and-mortar businesses to a minimum. 'Mortar' represents the offline world: traditional businesses recognizable by a retail POS sign, customer loyalty, high physical organisation costs, well defined distribution networks, stores and distribution centres or warehouses and customer-handling processes. The concept of click-and-mortar represents the ability to integrate the two worlds (online and offline) and create the ideal combination ${ }^{5}$.

\section{The Integration of Online and Offline Distribution Channels: Benefits of a Multi-Channel Approach}

The opportunities generated by the Internet in devising distribution policies must be analysed, according to Simon, with reference to two main aspects: product characteristics (non-digital, digital or digitalizable) and the number of customers (or transactions) ${ }^{6}$. It is indeed by combining the two aspects that a better understanding of Internet-based distribution potential can be obtained. The most beneficial situation is represented by digital or digitalizable goods that can be the subject of a great number of transactions. Fewer benefits should be expected in the case of non-digitalizable products with a limited number of customers.

Both the transaction volume and the number of customers present in the market have a cumulative effect on the cost reduction achievable through Internet. The success obtained from online sales of communication products and services (such 
as software, music, etc.) derives from the specific nature of these goods. Moreover, some types of services are also traded profitably online due to their characteristic intangibility. Among the most beneficial physical goods are those for which transportation cost is small compared to total cost, or goods not requiring the use of the senses that Internet cannot satisfy: touch, smell and taste.

Notwithstanding the problems related to conflict of channels that can appear when online distribution is introduced, and the danger of relationships with commercial partners who are threatened by the fact that middlemen get replaced by new technologies, click-and-mortar businesses seem to represent a model that allows for operation on the net without facing the typical managerial problems of Internet pure play businesses. Indeed the following benefits can be obtained:

- Company name. Businesses already present in traditional markets have a company customer awareness that can be used online without significant additional investments, while start-up companies must employ many resources in achieving a suitable level of awareness. The trust placed in wellestablished offline brands also allows consumers to overcome natural suspicion toward the Internet.

- Customer base. Start-up businesses, besides having to build all of the business from scratch, do not have a customer base. On the contrary, a business that has been established for some time in other channels allows click-and-mortar companies to target communication and promotional activities at its customers. Indeed it is much easier to obtain a response from customers who have already had a positive purchase experience and hence a certain degree of trust in the company and its products.

- Knowledge of demand. An online distribution channel has specific peculiarities in its approach to customers. However, businesses already operating in other channels possess information about the preferences and habits of their customers that allow the business top concentrate on the true needs of consumers and avoid bad choices and wasted resources.

- Profitability. Start-up companies are often influenced by the need to quickly reach high levels of profitability and thus produce a return on the capital invested. Click-and-mortar companies, on the contrary, can tolerate periods of sales below the break-even point on the online channel, since they can count on profits coming from the traditional business. A series of implications on management costs should be taken into account for clickand-mortar companies, in particular related to: transportation ${ }^{7}$, delivery of goods $^{8}$, warehouse management ${ }^{9}$, carrying out orders and informationrelated activities ${ }^{10}$, management of the returns ${ }^{11}$.

- Well-established infrastructures and distribution logistics. The delivery cost of digital or digitalizable goods is extremely small, while the delivery of physical goods implies a higher cost exasperated by expectations of evershorter delivery times by consumers. Delivery from the physical store closest to the customer could represent the ideal distribution centre, and also the place where the product can be returned.

- Reaching markets not yet served or complementing an existing market offering. For companies not provided with their own physical distribution network, it might not be considered beneficial to open points of sale in markets in which the necessary investments and the related cost are not compensated by adequate sales projections. The potential to activate an online presence allows for the overcoming of spatial and temporal barriers 
through forms of virtual ubiquity and reaching potential customers worldwide at any time, at a limited cost. In markets already served, it becomes possible to supplement what is offered by expanding the range of products (for example, low turn-over products or products not often requested by customers), or time availability (for example seasonal products, that might not be available at certain points of sale).

The introduction of changes in the distribution system presents many difficulties, deriving from the presence of a well-established organisation, tested over time and characterized by situations of equilibrium within the company, with external commercial partners and institutions. All innovations tend to disrupt such equilibrium, thus generating problems that must be given careful consideration. When Internet is the newly activated channel these include:

- Distribution costs related to multiple channels. Few companies are in a position to replace all other sales channels with Internet, thus revolutionizing the distribution organisation. Usually, the net is introduced instead as an additional channel, complementing the existing ones. The use of technology has the potential benefit of reducing costs, even if it initially implies an increase in the resources employed, and produces benefits only in the medium to long term. Cost containment can be achieved by using the net to sell new products and services, for which no established sale processes exist. The use of Internet-based distribution channels would thus be justified by the progressive coverage of new markets, and a possible change to the existing organisation could be delayed into the future, when suitable financial equilibrium conditions have been reached.

- Different channel margins. A multi-channel distribution strategy usually requires the adoption of different sales prices. The needs expressed by markets can differ depending on the modes in which products and/or services are made available to purchasers. Various reasons can suggest decreasing the price of products sold through Internet-based distribution channels. The development and success of Internet-based electronic commerce is restrained by the prudent and fearful attitudes held by the demand, as is often the case for new technologies. The abandonment of well-tested distribution systems must be motivated by immediately verifiable benefits. A price cut is the simplest way to overcome many fears. On the other hand, a reduction in sales prices does not necessarily have a negative influence on the total net income, since the costs related to the Internet-based selling channel can be significantly lower than traditional distribution channels costs. The impact of such a development leads to a change in the whole cost structure for an industry, with effects to all distribution channels. A typical example is Amazon.com ${ }^{12}$.

- Establishment of channels with hybrid features. The use of Internet in distribution produces competitive advantages easily implemented by the various parties, with limited investment, thus allowing for the expansion of businesses into functions and services previously the exclusive domain of other types of commercial intermediaries. For example, a retailer can continue its traditional sales activity, and at the same time add services that were previously under the exclusive control of wholesale dealers (such as making a larger selection of products available through an Internet site). In the same way a wholesale dealer can continue its business while 
complementing it with online retail sales. This is made possible by the fact that final purchasers can easily identify and contact the dealer. Distribution intermediaries could also take up functions previously belonging to manufacturers, such as advice and support on the products sold.

$\square$ For example Ingram Micro, the largest wholesale dealer in technology products and services, allows its customers to access databases concerning the products it distributes, including notes, technical data, etc. ${ }^{13}$. With this development Ingram Micro offers one of the largest and most up-to-date sources of information about technology products.

Besides the potential for expanding the typical characteristics of specific distribution channels, new organizations also have the opportunity to enter traditional channels and introduce service innovation.

For example, companies, such as Microsoft, involved in software development and other activities related to the computer industry are able to exploit their technical skills to penetrate the distribution channel by providing a source of information for products traditionally far from their core business. Microsoft thus created a website from which potential customers can obtain specific information about purchases of cars, financial products and travel packages ${ }^{14}$.

- Channel fragmentation. Channel fragmentation derives from the inability of companies to change their organizational structure and work processes to respond to changes emerging from the introduction of Internet. An example of these difficulties is the inability to integrate the communication flow represented by e-mail into existing processes ${ }^{15}$. Instead of the establishment of a unified, integrated communication channel, fragmentation can ensue due to the inability of marketing managers to coordinate their network business activities. Lack of coordination can be the source of significant problems for a company's business. For example, prices left unchanged on the Internet site when they instead have been modified offline can create confusion among customers and substantially damage brand image. The introduction of a new channel creates new channel management problems, if existing distribution channels have to be reconciled with the new electronic channel. The progressive replacement of traditional with electronic channels can be assumed for digitalizable products, while for the products for which pre- and post-sale services and logistics are of importance, situations of complementary coexistence should be assumed ${ }^{16}$.

The typical example is Barnes and Noble, which chose to set up a new division that was completely separated from the physical retail network. However, it lost more than it gained, for example in the opportunity to promote the barnesandnoble.com site in its stores.

Every company must adopt a specific click-and-mortar strategy related to its own market by taking the existing competitive situation into account and identifying aspects to be integrated and ones to be left separated. At the operational level, 
integration should be based on the strengths of the existing distribution network. In particular, integration can allow for lower costs or the establishment of sites that are richer in information, or become a competitive advantage over pure-play competitors. Separation allows a company to establish systems with fewer limitations and develop sophisticated specific tools.

\section{The Limits of Multi-Channel Strategies: the Danger of Conflict}

In many industries, some companies have recognized the potential for Internetbased development, while others respond to the competitive threats posed by startup companies ${ }^{17}$. Companies that have started e-commerce projects must take care while running multiple channels to anticipate and eliminate any possible conflict between existing channels and new ones created online ${ }^{18}$. It is not easy to identify suitable solutions, especially because of the lack of well-tested and easily imitated examples. Among the solutions that have been proposed, the one by the consulting firm Arthur D. Little calls for three successive stages in the introduction of ecommerce:

- Assessment of the existing channels, with attention focused on the relationships established with commercial partners, or through them, with customers.

- Identification of potential conflicts between channels.

- Design of new online channels while trying to minimize possible conflicts.

\section{Assessing the Existing Channels}

One of the most important differences between traditional companies and socalled Internet based companies is that the latter do not have other distribution channels and therefore are not subject to conflict with existing channels. Instead, companies that do have traditional distribution channels must try to minimize potential conflict with the pre-existing distribution network. Following Michael Porter's analysis ${ }^{19}$ of the 'five forces' of the market, the assessment of the channels already activated can be performed by establishing: which types of channels are already activated, which one is the main channel, which products or services are distributed by each channel, which channels serve the same market and which ones have their own target market, which ones are partner channels and at what level it is possible to control them.

\section{Identifying Potential Conflicts between Channels}

In the second stage a company examines the potential conflicts deriving from the creation of new online channels and distinguishes between internal and external conflicts. Internal conflicts manifest themselves between two or more channels dedicated to the same market. External conflicts involve third parties. Direct channels are almost exclusively subject to internal conflicts, while indirect channels manifest both internal and external conflicts.

\section{Internal Conflicts}

Four types of internal conflict can be identified, often cross-correlated. 
1. Cannibalisation between channels. The creation of a new distribution channel almost inevitably leads to the redistribution of the total sales volume among the different channels, automatically giving rise to the cannibalisation of existing channels by the newly formed ones. In organizations with an orientation toward channels rather than toward customers, friction amongst the different channel managers emerges. Incentives are usually tied to the volume moved through the sales channel. Therefore each channel tends to maximize its sales volume, even if this damages the other channels. The danger of cannibalisation does not only involve Internet, but becomes more evident when a new channel is activated ${ }^{20}$.

2. Under-utilization of property. Traditional sales channels need various kinds of physical structures: warehouses, branch offices, call centres, etc. The optimisation of the number, size and use of these resources is crucial since they generate a high proportion of total company costs. Therefore, if a sizable fraction of the manufactured volume were to be transferred onto the online channels, the cost structure would be changed, with possible significant negative effects on corporate income.

\section{This is the case of Barclays Bank ${ }^{21}$, a leading bank in the United} Kingdom. Following the success of banks offering their services online, Barclays decided to close about 700 of its branches all over the United Kingdom. Through the concentration of the business on the Internet, the remaining branches represent a fixed cost for physical structures that is actually superfluous, thus negatively influencing corporate profitability.

3. Price conflicts. Online prices tend to be substantially lower than for other channels, since the former - usually referred to Internet based companies benefit from lower primary costs and have lower margins than what is considered acceptable by traditional companies. Companies operating with a multi-channel system are the first to face this problem: to remain competitive online they must accept the prices imposed by online competitors. This policy, however, also influences prices through other channels. Customers can hardly accept different prices for the same product sold by different channels. Therefore, the company is forced to adjust the prices for all channels. However, a policy of price differentiation, when planned, can be an excellent tool to transfer customers from traditional and more costly channels to online channels.

$\square$ Charles Schwab, a multi-national financial firm, used this technique by fixing the online fee for the sale of apartments at \$29.95, while the offline fee was $\$ 60$. This policy was designed to motivate customers who usually closed contracts by phone or by showing up at the various branches in person, to use Internet instead. Saving \$30.05 on fees turned out to be an excellent incentive to try the new form of selling.

4. Unsynchronised channels. Using a brand in the dot.com version of the company without any ties to the 'traditional' company can undermine success in the online channel. Indeed, customers tend to perceive the company as a whole, independently of the distribution channels: they just choose the most advantageous one, without considering the potential that 
they could be run by independently managed companies. On the contrary, they expect a certain degree of integration between the online and offline channels.

Barnes and Noble, the largest bookstore chain in the United Kingdom, and barnesandnoble.com offer an excellent example of unsynchronised channels ${ }^{22}$. Even if Barnes and Noble owns only $40 \%$ of barnesandnoble.com, customers generally ignore this fact and believe that the company is the same. Therefore many barnesandnoble.com customers are confused when they realize that they cannot return a book bought online at a BarnesandNoble store, or use a coupon acquired through the Internet to purchase a book in a traditional store.

A clear separation between the online channel and other channels can also create problems in the management of information obtained from customers. One of the main advantages of the use of Internet in e-commerce is the ability to obtain a wide range of information from visitors to the site and purchasers that is useful for the more targeted management of promotions and communications. The creation of an online channel operating completely independently from the traditional business prevents the full exploitation of opportunities offered by the new technologies.

\section{External Conflict}

Three main sources of external conflict can be identified:

1. Establishment of a direct sale channel by manufacturers. Manufacturers using indirect channels to reach markets can, using Internet, supplant intermediaries. The setup of a direct sales channel could hence be opposed by indirect sale organisations. These commercial partners could actually abandon the company and switch to the competition, thus determining sizable negative effects for the business as a whole. In most industries, most sales are still made through traditional channels, and therefore companies must decide whether to risk losing revenues and the relationship with external organisations to establish direct channels based on e-commerce technologies.

Compaq Computer recently faced this problem. Having lost its leading position in PC sales, Compaq decided to imitate its competitor Dell Computer and sell its product directly using e-commerce. This choice put Compaq in a situation of direct competition with its wide distribution network, both wholesale and retail, with negative consequences to the commercial relationships established previously. Trying to best manage the situation thus created, Compaq tried to protect its dealers by eliminating the new forms of intermediation set up by pure Internet companies23.

2. Loss of control over sales channels. Even if companies seldom control the relationship with customers directly, they try to control their sales channels through: the establishment of planned sales areas, the distribution of operational guidelines to the retailers, product presentation and promotions. 
These forms of control become very difficult to apply, however, if the distributors choose the online channel as a distribution method. For example, it becomes almost impossible to verify whether authorized dealers sell outside their assigned area.

For example, Montblanc, manufacturer of high quality pens, instructed its retailers not to sell online. According to a statement by Montblanc 'Luxury by its very nature is not ubiquitous, and that's why, by its very nature, it doesn't make sense for it to be on the Internet'. In any case Montblanc must activate specific, precise forms of internal control to ensure that its retailers do not sell online, and must invest significant financial and human resources to this end.

3. Shifts within the value creation chain. Even when manufacturers decide not to sell their products directly online, the presence of Internet sites determines a change in the relative strength of the partners operating in the distribution network. Very important functions, such as the information provided by dealers to customers can now be implemented directly by the manufacturer, thus changing the value creation chain and redefining the role of dealers very significantly. The automotive industry offers an important example of this mechanism. The online search for information about cars has become a wellestablished part of the car purchase process. The important role of the dealer thus disappears, reducing his importance and hence his contractual power with respect to the parent company.

\section{Designing an Online Channel while Minimizing Conflicts}

The importance of channel conflicts depends largely on the role assigned to the online channel. If the latter is a complementary channel with respect to the traditional distribution organisation, its negative impact could be minimal. If, on the other hand, it threatens to replace other channels, it could create friction with commercial partners. Moreover, different situations are determined when the same products are offered through the Internet and traditional channels, possibly with the same brand, and instead when new products are sold to new customers with new brands. The former option can easily create internal pressure, while the latter could be harmless to the relationship amongst managers of the various channels. The establishment of an online sales channel must take all of the alternatives mentioned above into account.

Vauxhall, for example, developed six models to be sold exclusively online, with small differences compared to models available through the traditional dealer showrooms in order to prevent price comparison.

\section{The Management of Competitive Market Spaces: the Concept of 'Meta- Market'}

In multi-channel distribution strategies the use of e-commerce is aimed at rationalizing distribution processes to seize the opportunities for significant cost reductions and the expansion into new markets or new market segments. The start 
to many e-commerce initiatives required a re-thinking of market competition spaces amongst other things, even the industry and corporate boundaries. In 'virtual' space competition, threats can come from new parties, who by putting their offering online can go beyond the boundaries of traditional market sectors and acquire new customers and their loyalty.

Even the notion of corporate boundaries can acquire new meaning when the forms of partnership between an online company and an offline company are unusual and functions are assigned to each innovatively.

E-commerce also permits the offering of new types of services and benefits to customers, and creates new opportunities for knowing their preferences. Moreover, it facilitates upstream and downstream integration processes, thus allowing for cost reductions that can be transferred to customers. For example, regarding distribution, it becomes possible to rationalize the processes involved in the physical transportation of goods to the final user, by the integration of existing infrastructures with suitable information systems. The final purchaser is presented with a larger and different choice of services: from information about the availability of products in warehouses, to home delivery, and from the potential to check order status, to access to the sites of companies located all over the world.

Difficulties in the distribution of physical goods characterizing e-commerce can be partly overcome using the click-and-mortar solution through the integration of real and virtual points of sale (for example, allowing goods bought through the web to be returned to the physical points of sale). This permits restoration of the sensory experience belonging to the brick-and-mortar world: the interest in shopping, the chance to touch, hear, smell and taste products, and the ability to entertain - which represent the potential of onland retailers ${ }^{24}$.

Therefore, the concept of a market in which competition takes place in physical spaces evolves toward a competitive situation where the dynamics take place in a virtual space. Such space is meant not only as a virtual place (market-space) replacing the physical place (marketplace), but also as a new form of competition taking place through the meta-market, whose boundaries are defined by the cognitive spaces of the customer ${ }^{25}$.

A new player entering the market can thus assume the role of new intermediary between customers and the players already present, redefining the market boundaries and creating new forms of competition. This can also be done through a change in negotiation power: by facilitating direct contact, e-commerce can modify the market power structure. Customers can end up with higher negotiating power associated with their role as purchasers. The key factor in this change is the information asymmetry created by e-commerce.

\section{Bibliography}

Berquier-Gherold Valerie, De l'infomédiarie au 'portal communautaire': restructuration del marchés et protection de la vie priveée, in: La protection de la vie priveée dans la société d'information, Paris Presses Universitaires de France, Paris, 2000.

Brondoni Silvio M., Comunicazione, risorse invisibili e strategia competitiva d'impresa, S.M. Brondoni (ed.), La comunicazione d'impresa, Sinergie, CUEIM, Verona, n. 43-44, 1997.

Brondoni Silvio M., Brand Policy and Brand Equity, Symphonya. Emerging Issues in Management, (symphonya.unimib.it), n. 1, 2000-2001.

http://dx.doi.org/10.4468/2001.1.02brondoni 
Colla Enrico, La grande distribuzione in Europa. Evoluzione delle formule distributive, strategie e strutture aziendali, rapporti con l'industria, ETAS Libri, Milan, 1995.

Collesei Umberto, Marketing, II ed., CEDAM, Padua, 1994.

Corniani Margherita, Sistema informativo aziendale e dinamiche competitive, Giappichelli, Turin, 2000.

Golinelli Gaetano M., L'approccio sistemico al governo dell'impresa. L'impresa sistema vitale, vol. I, CEDAM, Padua, 2000.

Golinelli Gaetano M., L'approccio sistemico al governo dell'impresa. La dinamica evolutiva del sistema impresa tra economia e finanza, vol. II, CEDAM, Padua, 2000.

Gulati Ranjay, Garino Jason, Get the Right Mix of Bricks \& Clicks, Harvard Business Review, vol. 78, n. 3, May-June 2000, pp. 107-114.

Lambin Jean-Jacques, Market-Driven Management, Macmillan Business, London, 2000.

Lindstrom Martin, Clicks, Bricks \& Brands. The Marriage of Online and Offline Business, Kogan Page, London, 2001.

Marchet Gino, Melancini, Marco, Perego Alessandro, Strategie distributive per il commercio elettronico B2C, in Logistica Management, March 2001, pp. 81-96.

Simon Hermann, Seven E-Commerce Lessons, European Business Forum, n. 7, Autumn 2001.

\section{Notes}

1 Brondoni Silvio M., Brand Policy and Brand Equity, Symphonya. Emerging Issues in Management, (symphonya.unimib.it), n. 1, 2000-2001.

2 Berquier-Gherold Valerie, De l'infomédiarie au portal communautaire: restructuration del marchés et protection de la vie priveée, in: La protection de la vie priveée dans la société d'information, Paris Presses Universitaires de France, Paris, 2000.

${ }^{3}$ According to Ghemawat distance is actually a multi-dimensional concept, made of geographic or physical distance, administrative distance, financial distance and cultural distance.

${ }^{4}$ Martin Lindstrom, Clicks, Bricks \& Brands. The Marriage of Online and Offline Business, Kogan Page, London, 2001.

${ }^{5}$ Martin Lindstrom, 2001, cit.

${ }^{6}$ H. Simon, Seven E-Commerce Lessons, European Business Forum, Issue 7, Autumn 2001.

7 The most evident aspect, which seems to most clearly distinguish e-commerce from the 'traditional' forms of commerce, is the need for the vendor to take care of transportation and delivery of the goods to the final purchaser. It is the most critical aspect, since the physical delivery of goods represents one of the most serious problems causing a slower growth of business-toconsumer e-commerce than expected or hoped for.

${ }^{8}$ For all products requiring physical delivery, the sustainability and profitability of business models based on business-to-consumer e-commerce largely depend on the ability to organize and manage the logistic process. Such a process begins with receiving the orders and ends with delivering the products to consumers, including also the post-transaction processes such as the possible return of goods for example. The main variables involved in the distribution process are: the configuration of the distribution network, the modes of transportation from suppliers to nodes and between different nodes, the modes of distribution to final customers, the make or purchase choices, the mechanisms of management of the flow of products, the diversification of the flows according to the type of product and/or order. The largest source of dissatisfaction among customers purchasing online is, in fact, the inability of the companies operating through the digital channel to deliver products and provide services quickly and cheaply. Final purchasers expect quick deliveries more and more often, not just 'the following day' but 'the same day', in the same way that they are able to obtain plane, hotel and car rental reservations. The critical factor for the logistic models of 
Rapid and Very Rapid Order and Delivery Virtual Organizations is the establishment of strategic alliances and partnerships.

${ }^{9}$ Distribution can be supported by real or virtual warehouses: in the former solution the e-tailer manages its own warehouses for storage and carrying out orders, in the latter the suppliers' warehouses are used. Mixed solutions can also be used: warehouses can be used for the storage of some items, and transit and consolidation for other items. Transportation from warehouses to customers is entrusted to door-to-door delivery operators. When considering the two solutions, the strong points of distribution through real warehouses should be stressed: the direct control over several activities directly influencing the level of service perceived by the final customers, and the potential of setting up the handling and distribution activities based on the specific characters of ecommerce. Real warehouses imply a higher level of risk since they require: a) initial investments in fixed capital for the warehouse, which needs personnel, storage and handling infrastructures, computer systems, etc., and b) investment in circulating capital for financing the stocks, with the related risks of obsolescence or depreciation of the goods.

An intermediate solution consists of keeping stock of some goods, and building stock at the suppliers' for other goods. Assessment of the latter goods must keep the reliability of the supplier, the specific storage and handling requirements of the products, and the cost of maintaining product stock into account. For example, it is usually not advantageous to stock those products which require high maintenance costs or a high level of storage and handling specificity, and which can be obtained from reliable suppliers (Marchet et al. 2000).

${ }^{10}$ Significant information synergy can be obtained by an integrated management of online and offline sales networks. For example, it is possible to obtain: information about Internet users and the preferences they expressed about the products, data on sales, purchase frequency, consumer trends, brand purchased and average bill. All of these data can be gathered both in stores and from the Internet site, thus obtaining further information about the differences between the results obtained in the real and the virtual channel. It is thus possible to determine which products sell better online and which offline. Also information about products most often returned is important: it is essential to identify such products and understand why they are returned. These indications can be interpreted differently depending on the product. Indeed problems can concern materials, lifetime, and so on. When users register their data on the Internet site it is possible to obtain other important indications (such as demographic data) that can also be useful in deciding to set up promotions, thus achieving a high level of customisation. Virtual marketing techniques can thus be applied (for example, through virtual postcards) with the effect of propagating the knowledge about the existence of the company's Internet site.

${ }^{11}$ A solid off-line presence is important to manage the return of goods bought online that the customer does not want to keep and thus pay for. The final purchaser must be able to go to a physical location (a store or another type of location) to return the products or possibly replace them. For example, the impossibility of returning books bought online to the stores puzzled the customers of Barnes \& Noble, which had pursued a policy of total separation between physical and virtual sales networks, thus losing essential synergy between the two channels. The awareness of the importance of PoPs (Points of Presence), that is the physical locations where the customer can see the products sold online or return them and find assistance, represents a clear competitive advantage over the click-and-mortar model and the management of multiple channels compared to the model of pure play companies.

12 The distribution organization of Amazon.com revolutionized the publishing distribution industry. Offering books at a lower price, allowed for by the reduction of storage costs, is one of the most interesting innovative elements.

\footnotetext{
${ }^{13} \mathrm{Http}: / /$ www.ingrammicro.com

${ }^{14} \mathrm{Http}: / / \mathrm{www} . \mathrm{msn} \cdot \mathrm{com}$
}

${ }^{15}$ Research on the topic (see P. May, E-business, 2000) shows that the probability of obtaining a quick reply to a request for information about a product sent through the Internet is about $50 \%$. This problem is not limited to a certain industry sector or a given corporate size, but is a very common problem that companies ought to solve to avoid providing disservice to their customers. It is still to be understood why companies do not respond to the communication traffic generated through the 
Internet, after having spent significant financial resources in trying to encourage and spread the use of new technologies and their Internet sites.

16 The opportunities deriving from the integration of physical and virtual distribution are well described by Gulati and Garino. According to these authors the problem of the potential of such integration is not to be posed anymore. The problem to pose instead is the mode in which such integration should take place. They are far from the position of Christensen ${ }^{16}$, who stresses the danger of cannibalisation between a physical and virtual channel. After illustrating some examples of the various modes of integration between a physical and virtual distribution network (Office Depot and its OfficeDepot.com site, KB Toys and the joint venture with BrainPlay.com from which KBkids.com arose, Rite Aid and its partner Drugstore.com) they conclude that the benefits of integration are too important to be completely abandoned.

${ }^{17}$ Well known examples of this include Amazon.com, which forced Barnes \& Noble to create dot.com versions of itself, or E*trade, whose immediate success forced the Charles Schwab brokerage firm to completely revise its strategy. Later the success obtained by Schwab forced Merrill Lynch online to set up its Internet version, Merrill Lynch Direct.

${ }^{18}$ Regarding Benetton, for example, it is known that conflicts with the franchising networks were avoided through the integration with the megastore networks in the countries where a widespread franchising network does not exist. Indeed, not all countries are characterized by the same presence through franchising stores; consider for example the United States or the United Kingdom.

${ }^{19}$ Porter, Michael, La strategia competitiva: analisi per le decisioni, Tip. compositori, 1982.

${ }^{20}$ For example, the creation of Merrill Lynch Direct was met by the strong opposition of its powerful network of brokers for the reasons mentioned above. The brokers feared a significant reduction in revenues or their own obsolescence, since customers were offered the potential of managing their portfolios online.

${ }^{21} \mathrm{Http}: / /$ barclays.co.uk

${ }^{22}$ In a recent public statement barnesandnoble.com announced that the two companies are working to achieve a higher level of integration. It must also be noted that many of the problems between Barnes and Noble and barnesandnoble.com are due to the fact that the management of Barnes and Noble was under pressure to quickly create a web site and thus react to Amazon.com as soon as possible and limit the loss of customers.

${ }^{23}$ These terms denote companies performing intermediation directly and exclusively online.

${ }^{24}$ Contrary to a widespread belief in the predominance of Internet pure play companies on the net, the data show a very different reality. In an analysis by dotcom.com, a company monitoring the web, there are definitely more click-and-mortar companies than start-up companies. The following graph clearly shows the numerical prevalence of companies having both an online and a physical traditional organisation. At a time when start-up companies are going through a serious crisis the formula appearing to be winning, is the integration of the online business with the business implemented through a physical organisation.

${ }^{25}$ Dimitriadis S., Chapelet B., Deglaine J., Matmati M., The Integration Of Electronic Commerce, Centre Time, Group ESC Grenoble, 2003. 